\title{
"Teaching Experience Preferred?" Preparing Graduate Students for Teaching Opportunities Beyond North America
}

\author{
Suzanne Le-May Sheffield \\ Dalhousie University
}

Over the last 15 years, graduate students applying for academic positions in post-secondary education have increasingly been asked to include a statement of teaching interests, a teaching philosophy, or a teaching dossier with their applications. Even if a potential employer does not request any of these documents, many interviewees are expected to be able to reflect and articulate intelligently about their teaching philosophy in a job interview andlor to demonstrate their teaching. In Canada and the United States, research has shown that hiring committees are looking for candidates that not only have teaching experience, but who can also talk about and demonstrate their teaching (Meizlish o Kaplan, 2008; Schonwetter, Taylor, \& Ellis, 2006). However, what types of teaching documentation are required of applicants when they are applying for entry-level academic positions outside of North America? Especially as developing countries are increasingly seeking Canadian faculty for their experience in student-centered pedagogical approaches (Tamburri, 2011). In addition, North American graduates are searching global markets for further career opportunities. An investigation was launched to examine permanent, tenuretrack academic positions on six job sites during a four-month period to compare requests for teachingrelated materials and teaching experience in job ads beyond North America. This study found that the international job market is comparable to the North American one with respect to teaching expectations and documentation. These findings underscore the importance of graduate student teaching development for those graduates seeking academic employment outside of North America.

\section{Introduction}

$\mathrm{n}$ a 2011 article published in University Affairs,
Rosanna Tamburri argued that, "Canadian professors are highly sought-after for their expertise in curriculum development. They are helping to transform postsecondary education in developing countries..." (p. 24). In their 2003 study of 30 British academics, Richardson and 
McKenna highlight the value of international experience both to the individual's career advancement and to the institutions that hire them, abroad and at home. Overseas faculty positions are advertised in key English language job sites. This globalization of the academic job market raises a new question for North American educational developers who support the teaching development of graduate students: How can we best advise graduate students to prepare their applications for positions beyond North America with respect to their teaching?

Over the last 15 years, increasing emphasis has been placed on the teaching development of graduate students in educational development work as expectations for junior faculty's teaching experience and abilities has increased. Research in the Canadian and American context has demonstrated that hiring committees are looking for candidates who have teaching experience and who can talk about and demonstrate their teaching abilities and approaches during a job interview (Meizlish \& Kaplan, 2008; Schonwetter, Taylor \& Ellis, 2006). This research, in the context of the globalization of academe, raises the question of whether positions outside of North America hold the same teaching expectations for new hires.

This pilot study has found that the international academic job market does indeed appear to parallel the North American one in its expectations for teaching experience and documentation for entry-level positions. These findings underscore the importance of educational developers' work with graduate students to support and encourage their professional development of teaching to provide preparation for their job search for international positions as well as within Canada and the US.

\section{Approach}

Two hundred ninety-five job ads were scanned for permanent, entry-level, traditional tenure-track academic positions from six job sites between December 2010 and March 2011. The job sites accessed included: Inside Higher Ed (US), HigherEdJobs (US), The Times Higher Education (United Kingdom), Australian Jobs (Australia), UniJobs.com (Australia), and CareerEDU (Europe). Sites were visited on a regular basis during the 4-month period for jobs advertised outside of North America. During data collection the following information about each position was recorded:

- name of institution, position title, faculty, country, date of posting, and date of closing;

- responsibilities of the position;

- expected qualifications and experience required;

- documents requested from the applicant;

- whether or not there were any language requirements;

- specific teaching experience required; and

- whether or not a teaching philosophy statement, dossier or other documentation was required.

The data was then organized into four geographical areas: United Kingdom, Australia/New Zealand, international (non-Western countries), and Europe. 'International' included the following countries: Saudi Arabia, Egypt, China, United Arab Emirates, Kuwait, Lebanon, Qatar, Malaysia, Trinidad and Tobago, Bahamas, Fuji, Singapore, and Afghanistan. Within each of these regions, record was made of the number of positions requiring teaching as part of the position advertised; whether or not the position required teaching experience prior to taking the advertised position; if the job ad made reference to a request for a record of 'excellence;' 'dedication,' or 'high quality' with respect to teaching; and finally, whether or not, at this application stage, the institution required any kind of documentation of teaching experience or teaching qualifications.

\section{Results}

The quantitative results are most clearly summarized by the graphs below that demonstrate the results for each area of inquiry, by region, in numbers and by percentage (Figures 1-4).

The results of this pilot study clearly demonstrate several key findings. The first key finding is that in the majority of tenure-track positions across all geographic regions the chosen candidate will be expected to teach (Figure 1). In addition, a significant number of positions (over 50\%, excluding the United Kingdom) expect candidates to arrive having already obtained some teaching experience (Figure 2). The low rate for the United Kingdom may be explained by the fact that research is the focus of the doctoral degree and junior faculty are expected to engage in teaching development programs after they are hired. Furthermore, $20-50 \%$ of employers, varying by 


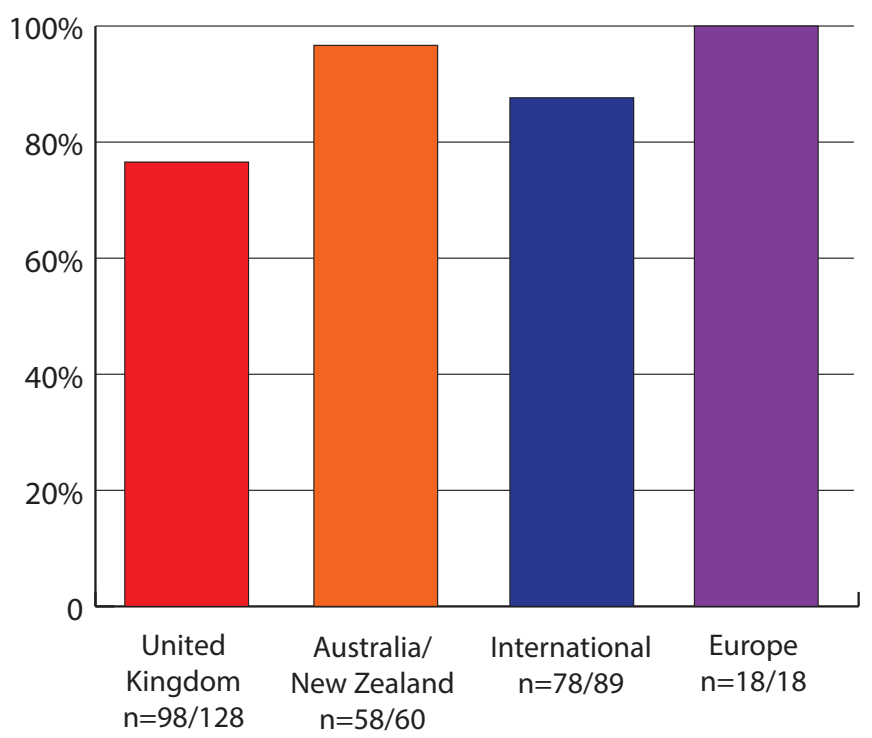

Figure 1

Teaching Required in Position

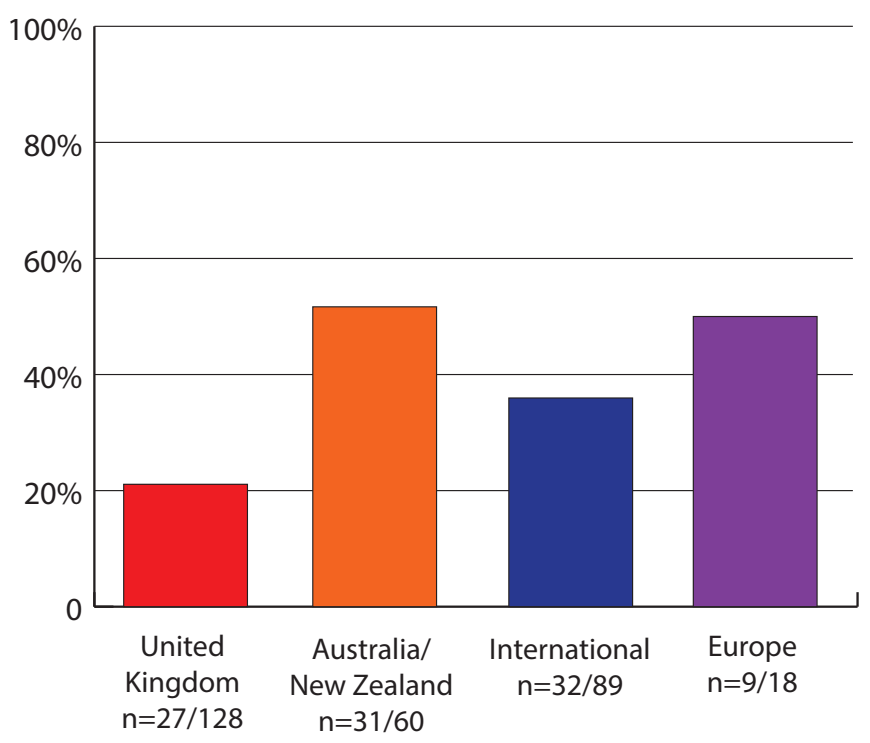

Figure 3

Record of Dedication to Teaching Excellence

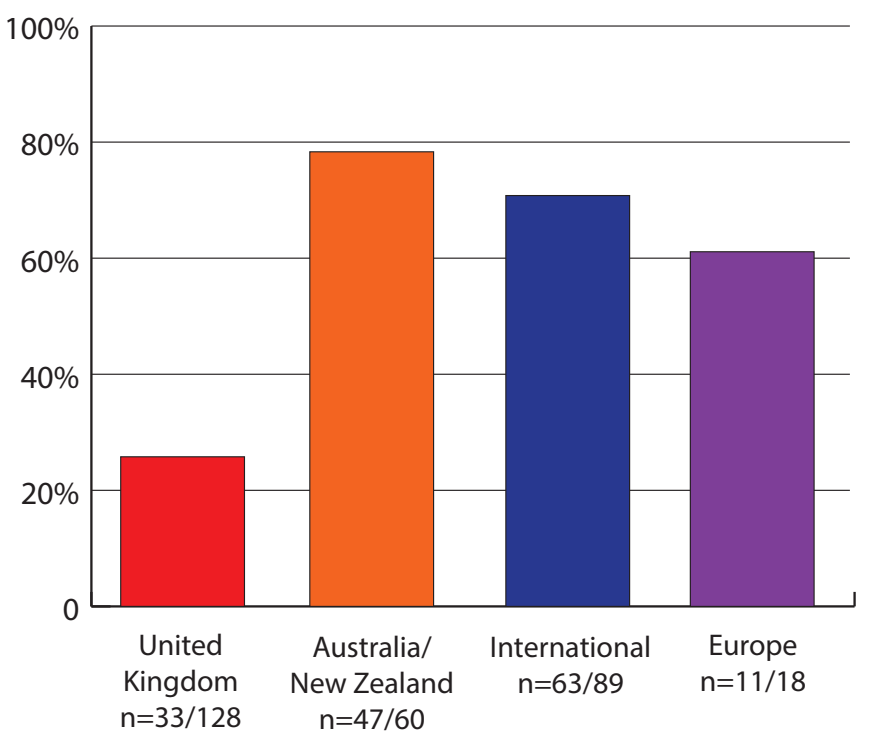

Figure 2

Teaching Experience Required Prior to Position

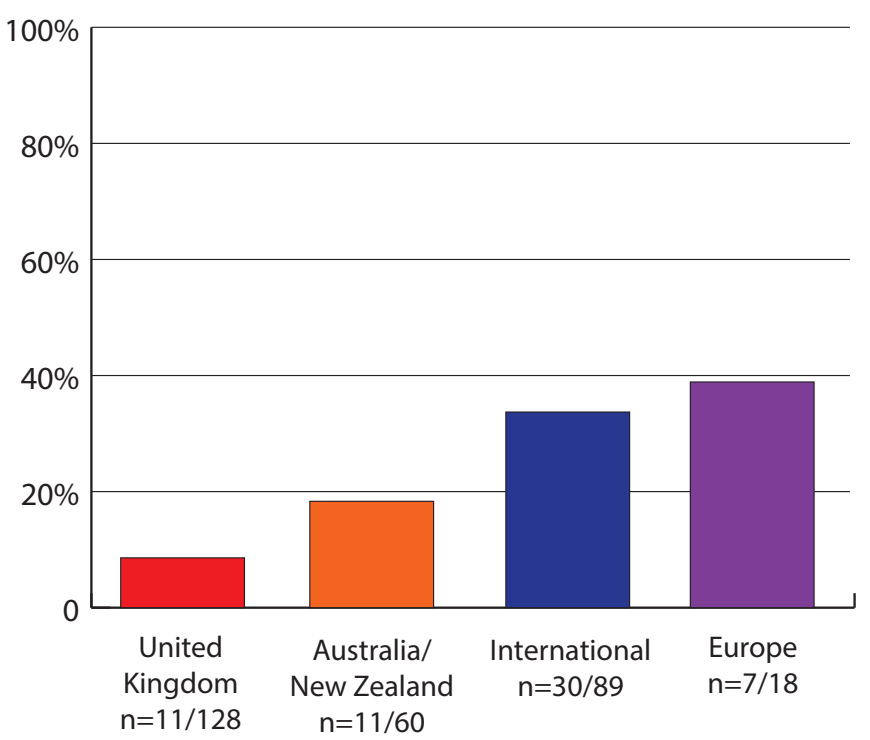

Figure 4

Documentation, Evidence, Certificate, or Qualifications Required 
geographical region, expect that their chosen candidate will be able to demonstrate 'excellence' in teaching, even at this entry level (Figure 3). Despite these requirements, however, the numerical data in Figure 4 demonstrates that, at least at the job application stage, hiring committees do not frequently request documentation of teaching experience, quality, or credentials, equal to the rate at which they say they expect these qualifications of the candidate. When documentation was required, requests ranged from teaching philosophy statements, to dossiers, descriptions of courses taught, and student evaluation data. A handful of jobs did say they required "certification" for teaching.

Job ads that outlined explicit teaching expectations varied by geographic region. For the majority of the Australian/New Zealand positions, the typical duties of a professor were listed. In contrast, positions advertised in the other geographic regions were not as specific, referring only generally to the expectation for teaching. In addition to listing duties, institutions advertising positions in Australia/New Zealand also frequently emphasized the extent to which the candidate would be expected to develop courses, curriculum, and programs, as well as specifying certain preferred approaches to teaching. They also itemized desirable teacher-characteristics they expected (i.e., collaborative, committed, enthusiastic). Further, 19 of the 60 Australian/New Zealand jobs ads included these additional teaching duties and characteristics. This inclusion of desirable teacher-traits in job ads was less noticeable in ads from the other geographic areas: 23 of the 128 jobs in the United Kingdom, seven of the 89 international positions, and four of the 18 European positions. However, where such characteristics are listed, the call for a student-centred approach, and the ability of the candidate to be innovative and inspirational, were often the focus. Perhaps surprisingly, reference to requirements to teach on-line courses, or to have experience and a willingness to teach blended courses was markedly absent. Possibly expectations for this specific kind of teaching is subsumed under the general context of teaching more generally.

International academic positions advertised on English language job sites reflected the global character of the position. Specifically with reference to the 'international' and 'Europe' geographical category, an additional language requirement was frequently requested with reference to teaching. In this study, 51 of the 89 international jobs included, required the candidate to be able to teach in a specific language (usually English) and, in some cases, also the language of that country. Similarly, 10 of the 18 job ads from Europe also requested language qualifications. Paired with this requirement, international job ads also made reference (in 18 of the 89 positions) to the need for the candidate to possess some experience, expertise, or willingness to respect a diverse student population and to practice inclusive teaching approaches. These figures were particularly striking when compared with those in the United Kingdom and Australia/New Zealand where language requirements and references to inclusive teaching practise were almost non-existent. These requirements in the international and European contexts suggest that the internationalization of faculty can potentially mean, as Welch (1997) argues, the "broadening of perspectives on teaching, learning and scholarship, the incorporation of specific cultural...skills not generally available in the host context, the building of tolerance and understanding among staff and students, and the revitalization of language instruction programs" (p. 324).

\section{Discussion}

The results of this research emphasize the need for educational developers to support the teaching development of graduate students prior to their first academic position, not only for the North American context but also for the international one. Moreover, the results also indicate the need for universities to provide teaching opportunities for their graduate students to gain experience before entering their first position. Such opportunities not only give graduate students an edge in the global job market but also provide them with invaluable experience that they can take with them into their first position. While development prior to the first academic position does not entirely prepare junior academics for their first appointment as they adjust to a new context and the fullness of academic life (Simmons, 2011), such development does go some way to providing a smoother transition from the role of graduate student to that of academic.

Educational developers might also, more specifically, consider how graduate students might best prepare to demonstrate 'excellence' in teaching in their job application. Although requirements at the job application stage for documentation of teaching excellence was low, expectations for the quality of teaching excellence were 
relatively high. Moreover, as Meizlish and Kaplan (2008) suggest, requests for documentation and demonstration of teaching can often increase at the interview stage. Where documentation and demonstrations were requested in the international context they mirrored the documentation required in the North American context. Thus the kinds of approaches taken by educational developers for the North American context including encouraging and providing opportunities for graduate students to develop teaching philosophies and dossiers; learning how to design a course; and providing opportunities for feedback on their teaching, both informally and formally, via student evaluation of instruction would also be relevant for the international context. The possibility that there will be an increasing demand for graduate students to provide evidence of teaching excellence through formal student evaluations of teaching, points to the importance of universities providing teaching opportunities via teaching assistantships and course directorships as part of the professional and teaching development of their graduate students. A number of employers in this study were also seeking candidates with experience in curriculum/program design and graduate student supervision - certainly two aspects of academic life that do not play a significant role in Canadian educational development programs for graduate students. This result might give educational developers and institutions pause to think about how graduate students could gain insight into both the curriculum development process and approaches to graduate supervision.

Transitioning to the context of another country's academic system would certainly add to the level of adjustment a new academic would need to make. Educational developers might consider how they could inform graduate students about the education systems in other countries. Graduate students in any particular institutions are often themselves a microcosm of the global community. Educational developers might, for instance, consider drawing on the experience of graduate students with international experiences to share their understanding of university education abroad. Whatever route is taken, graduate students need to understand the established teaching and learning cultures in different countries and to learn whether or not established approaches and philosophies are in the process of change elsewhere. In the specific case of North American candidates applying for international positions, it might be important for educational developers to encourage graduate students to understand the value of their past cultural experiences, and to appreciate the importance of expressing their attention to diversity and inclusivity in the context of the global job search. Educational developers could also play a role in encouraging graduate students to highlight their language proficiencies other than English and yet to understand the potential benefits of being an English-speaker in an international teaching and learning context.

\section{Limitations of the Study and Future Research}

The geographical results of this pilot study may be limited, if not by the overall number of job ads consulted then by the number of jobs included in the study in specific geographical regions, particularly Europe with only 18 jobs ads included. Another limitation is the restriction of the study to the job application process, not including the interview process. Nevertheless, as a whole, these results generally reflect the findings of previous studies of North American academic job ad requirements (Schonwetter, Taylor, \& Ellis, 2006).

Meizlish and Kaplan (2008), whose research included not only examining job ads but also surveying search committee members about the importance of teaching to their final hiring decision, found that further expectations to demonstrate and/or document teaching occurred at the interview stage of the hiring process. Additional research into expectations of hiring committees during the interview process for academic positions outside of North America needs to be undertaken to determine if the same increased expectations occur at this stage. In addition, research that determines whether requirements for teaching expectations, experience, and documentation change between disciplines, in particular at the interview stage of jobs outside North America, may also be appropriate. Further research, a few years from now, to determine whether or not there is an increased number of job ads expressing expectations for particular approaches to teaching and teacher characteristics will be of particular importance to educational developers designing and facilitating graduate students' educational development. One final opportunity for future research would be to consider the relationship between the expectations outlined for candidates in job ads and job interviews and the changing expectations for faculty in considering the awarding of tenure and promotion. The possibility that there is a relationship between increasing 
teaching expectations upon entry into the academy and those for tenure may be a strong one.

\section{Conclusion}

The results of this article underscore the need for the professional development of teaching in the graduate student years in preparation for academic positions in the global, as well as in the North American, context. Candidates for positions around the world must be able to articulate, demonstrate, and provide a record of teaching and, in a significant number of cases, must be able to present a record of excellence in teaching. The development of such teaching abilities could widen the career paths and opportunities for North American graduates. Despite the fact that Tamburri's (2011) article focuses on the desire for other countries to hire Canadian graduates for their pedagogical knowledge and abilities, my research also underscores the high teaching expectations for those graduates among international hiring committees. Educational developers in Canada are well-placed to ensure that our graduate students leave our institutions with the requisite skills and professional development mindset in teaching and learning to qualify as applicants for positions overseas.

\section{Author's Note}

With thanks to Godfred Chongatera and Janice Fuller for assistance with data collection and to Michelle Soucy for graph creation. As well, thanks to Dr. Lynn Taylor for clarifying the United Kingdom's practice of emphasizing research in the graduate years and placing teaching development in the early phase of an academic career.

\section{References}

Meizlish, D. \& Kaplan, M. (2008). Valuing and evaluating teaching in academic hiring: A multidisciplinary, cross-institutional study. The Journal of Higher Education, 79(5), 489-512.

Richardson, J. \& McKenna, S. (2003). International experience and academic careers - What do academics have to say? Personnel Review, 32(6), 774-795.
Schonwetter, D.J., Taylor, K.L., \& Ellis, D.E. (2006). Reading the want ads: How can current job descriptions inform professional development programs for graduate students? Journal on Excellence in College Teaching, 17(1\&2), 159-188.

Simmons, N. (2011). Caught with their constructs down? Teaching development in the pre-tenure years, International Journal for Academic Development, 16(3), 229-241.

Tamburri, R. (2011). Canadian style pedagogy takes root overseas, University Affairs, November, 23-25.

Welch, A.R. (1997). The peripatetic professor: The internationalization of the academic profession, Higher Education, 34, 232-345.

\section{Biography}

Suzanne Le-May Sheffield is the Director, Centre for Learning and Teaching, at Dalhousie University, and has a particular interest in the teaching development of graduate students. 